and a thin strip of paraffin wax or other hydrogen material is placed over the source. The number of $\mathrm{H}$-scintillations observed for a given absorption depends only on the amount of hydrogen, and is quite independent of chemical combination. This is to be expected, for the forces required to set the H-nucleus in rapid motion are enormous compared with the weak forces involved in chemical combination. We thus conclude that, for $\alpha$-particles of range $7 \mathrm{~cm}$., no $\mathrm{H}$-atoms from hydrogen in the free state or in chemical combination can be detected for an absorption greater than $30 \mathrm{~cm}$. of air.

The oxygen which gives no scintillations is now replaced by dry air. At once we observe for an absorption of $30 \mathrm{~cm}$. more than 100 scintillations per minute when for hydrogen we did not observe one. By adding mica screens we find that the scintillations cease for an absorption of $40 \mathrm{~cm}$. It is clear that these particles, which come from nitrogen, have a greater range than free $\mathrm{H}$-atoms bombarded by $\alpha$-rays, so that the effect observed beyond $30 \mathrm{~cm}$. cannot be ascribed to any hydrogen impurity in the nitrogen.

The air is now replaced by neutral oxygen, and thin foils of say copper, iron, silver, gold of stopping power corresponding to about $3 \mathrm{~cm}$. of air are placed suceessively over the source. Not a single $\mathrm{H}$-atom can be observed for an absorption of $30 \mathrm{~cm}$. A piece of aluminium foil is substituted and at once the number of scintillations jumps to more than roo per minute. Some of the scintillations are very bright, and we find that some of the particles are so swift that the absorption must be increased to $90 \mathrm{~cm}$. before the scintillations vanish. It is clear that aluminium must give rise to a number of very long-range particles.

Thus if we examine the number of scintillations beyond the range of ordinary $\mathrm{H}$-atoms, we are quite independent of any possible contamination of hydrogen in the material under examination. This is a great advantage, for we need not concern ourselves about the purity of the material as regards hydrogen. In this way, Dr. Chadwick and I have examined a large number of elements to test whether they emit particles of range more than $32 \mathrm{~cm}$. When the element was not available, a compound of the element with an "inactive" element like oxygen was used: The material in the form of a fine powder is dusted on a thin gold foil, an adhesive film being used so that the average absorption of the material corresponded with
$3-4 \mathrm{~cm}$. of air, and was then exposed to the source of rays. With the exception of helium, neon and argon, all the elements up to atomic weight 40 have been tested. No element of atomic weight greater than phosphorus, $3 I$, was found to give any effect, although it should be said that only a few of the elements of higher atomic weight have so far been examined.

A list of the elements examined in this way, from lithium to sulphur inclusive, is given in the following table. The second column gives the number of scintillations per minute per milligram activity of the source, namely, radium- $C$, for an absorption of $32 \mathrm{~cm}$. of air. These numbers afford only a rough comparison of the effects given by different elements, for the conditions of the experiment, for example, the thickness and distribution of the film of material, varied from element to element. The fourth column gives the approximate range of the particles.

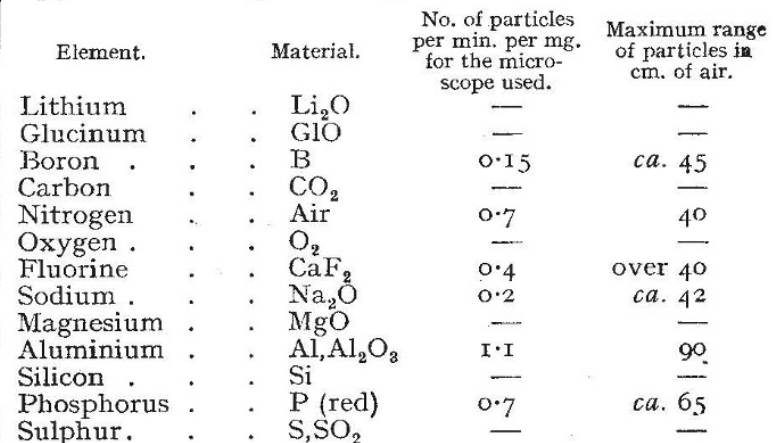

In addition to these, the following elements of higher atomic weight were examined: chlorine as $\mathrm{MgCl}_{2}$; potassium as $\mathrm{KCl}$; calcium as $\mathrm{CaO}$; titanium as $\mathrm{Ti}_{2} \mathrm{O}_{3}$; manganese as $\mathrm{MnO}_{2}$; iron, copper, tin, silver, and gold in the form of metal foils. In no case were any particles observed of range greater than $32 \mathrm{~cm}$. of air. The question whether any of these elements give particles of range less than $32 \mathrm{~cm}$. has not been examined.

It will be seen that the elements which give scintillations for an absorption of $32 \mathrm{~cm}$. are boron, nitrogen, fluorine, sodium, aluminium, and phosphorus. The numbers for boron and sodium were distinctly less than for the other elements.

(To be continued.)

\title{
The Royal Academy.
}

\begin{abstract}
THE representative of NATURE looking for points of scientific interest amongst the fourteen hundred or so annual exhibits at the Royal Academy may be excused if he sometimes feels depressed and is reminded of the proverbial searcher after a needle in a haystack, in so few of the pictures do objects having any direct connection with science appear. It has in past years been remarked that purely scientific work does not yet appeal to the Academy artist, and it is necessary to turn for points of interest to nature scenes such as may be found in pictures of sea, sky, snow, and country life.
\end{abstract}

In snow scenes J. Farquharson frequently has successful effects and "The Edge of the Forest" (239) this year is quite up to his standard. Another good snow effect, in this case associated with water, is contained in "A Yorkshire Bridge in Winter," by F. E. Horne (884). A successful landscape somewhat of the Leader type, the central feature of which is a group of pine trees, is shown by Frank Walton in 59r. It is a pity that there is only this one example of his work in the exhibition. The title which A. J. Munnings has chosen for No. III does not lead one to expect a landscape, but the setting of the portraits which give 
the name to the picture is a wide expanse of country with distant blue hills in the background showing delightful lights and shades. The effect is spoilt rather than improved by the somewhat wooden sitters so obviously posing in the foreground.

Turning to agricultural scenes, the two ploughs seem out of place alongside the rick in "Farm Lands in Sussex" (459) while hay still lies in the field uncarted. Again in "Harrowing " $(827)$ the crop seems to consist of heather, surely a somewhat unusual occupation.

In "A Summer Gale" (6ro) R. G. Brundrit has quite failed to convey the impression of a gale, ordinary cumulo-nimbus which might be associated with a shower being all that is indicated in the picture. The idea of a gale is introduced more effectively in Sir Arthur Cope's "An Evening in October " (750), though wind is not mentioned in this case. A very direct reference to the work of the Meteorological Office is made in "The South Cone" (250), though it is not indicated which of the two hundred gale warning stations round the British coasts is referred to. The warning seems to have been successful, judging from the flag at the masthead and the spray dashing against the shore, but the sea in the foreground, curiously enough, is scarcely rippled. The reference to a forecast in the title of I75, "A Hopeful Forecast," suggests further possibilities of reference to the work of the Meteorological Office, such as a forecaster studying the movements of Bjerknes' Polar Front, or plotting ships' observations received by wireless telegraphy from the Atlantic and deducing the probability of a week of fine weather. But any such expectations are destined to be disappointed, since what the picture reveals is a young lady with golf clubs tapping an old dial type of barometer, the hand of which is hard over in the "Set Fair" position.

Rain falling at a slant owing to the difference in velocity of upper and lower wind currents is a common sight, but Norman Wilkinson has shown the increase of wind aloft in a striking manner through the agency of falling rain in his picture of the King's yacht Britannia racing in a squall (395). The wind is blow- ing across the picture from left to right and making the yacht heel over until the mainsail is awash, while in a shower near by the rain slants backwards as it falls through air of diminishing velocity. One is almost tempted to commence calculating the rate of change of velocity with altitude.

An optical phenomenon figures prominently in "The Charcoal Burner's Hut" $\left(63^{2}\right)$, where bright coloured rings surround the moon at a radius which is too small for a halo, while of unusual size for a corona; but such varied optical forms have been seen in the sky from time to time that it is unwise to dogmatise upon the unreality of this representation.

Adrian Stokes' "Sunset" (188) is suggestive of a sun pillar in the bright vertical extension above the sun, though it is improbable that a real sun pillar was the source of his inspiration. The moonlit scene in 80 , " The Dead of the Night," is curious from the whiteness of the tower and wall in the moonlight and yet the absence of shadows where these would be expected under the trees.

Much interest naturally attaches to W. L. Wyllie's picture of the towing of the old Victory into her restingplace in dry dock. The execution of the water in Portsmouth Harbour is so good that the frame at the lower edge of the picture causes quite a shock, the eye being deceived by the reality of the representation. $\mathrm{J}$. Olsson has a pleasant sea and island scene in the Scillies (42), which gains greatly over some former works by restraint in the use of brilliant colouring

This year's exhibition is conspicuous for the number of portraits it contains, these forming a more than usually high proportion of the whole. It is gratifying to notice in a place of honour in one of the principal galleries, and adjacent to a painting of the Royal Wedding, a portrait of Sir Charles Parsons by Sir W. Orpen. Men of science are not numerously represented, and careful search was needed to disclose a tablet of Sir William Ramsay destined for Westminster Abbey and a silver medallion of Prof. James Thomson for Belfast University.

J. S. D.

\section{Obituary.}

Sir Patrick Manson, G.C.M.G., F.R.S.

THE death of Sir Patrick Manson, which occurred in London on April 9, has taken from the medical profession one of its most distinguished leaders. Born in 1844 , and educated at his native University of Aberdeen, Manson decided to follow his calling in the Far East, and in I866 went to Formosa, whence in I87 $\mathrm{x}$ he moved to China, where he continued during eighteen years. From the very beginning of his career Manson made the causation of disease his study. He was naturally interested in the elephantiasis so prevalent around him, but it was not until 1874 , when he came home to marry a wife, that he learned fully of Lewis's discovery of a microscopic filaria (now known as Microfilaria bancrofti) in the blood of Indian sufferers from the chyluria often associated with that disease.

On his return to China he settled down to the study of "elephantoid " pathology, and began with a survey of the blood of a thousand Chinamen. Having satisfied himself that the microfilariæ found in the blood are the issue of parent filariæ locked up in the lymphatics of the host-a discovery in which, however, he was anticipated by Bancroft of Brisbane-and that they are embryos incapable of any further development in the blood, he saw that the series of events by which the microfilariæ living in the blood of one man became the adult filariæ living in the lymphatics of other men must take place in the outside world, and might possibly be initiated by some such free-ranging, bloodsucking insect as a mosquito. His selection of the mosquito was decided by his further discovery that the microfilariæ make their show in the cutaneous blood of their host only after sunset, when mosquitoes are active ; in the daytime they flock to the host's lungs and central blood-vessels. In 1877 , with the compliance of an infected Chinaman, he put his theory

NO. 2740 , VOL. IO9] 